\title{
La influencia de Sebastián Serlio en las pinturas murales del convento dominico de Nuestra Señora de la Asunción de Yautepec, Morelos
}

Ligia

Fernández Flores CEPE-UNAM
Uno de los procesos artísticos más interesantes del arte virreinal de México, es el relacionado con la construcción de los conventos del siglo XVI, ya que a través de su estudio se pueden analizar numerosos aspectos vinculados con los proyectos misional es impulsados por los frailes. En este sentido, resulta de particular importancia entender cómo las técnicas y formas artísticas de Occidente fueron incorporadas y asimiladas por los indígenas para llevar a cabo no sólo la edificación de estos monumentales edificios, sino la manera de interpretar los model os queles fueron proporcionados para decorar las dependencias de estos núcleos conventuales, los cual es formaron parte integral de la vida religiosa y social de numerosas comunidades y pueblos.

Entre los conjuntos conventual es fundados durante el siglo XVI en la región del actual estado de Morelos, destaca el convento dominico de Nuestra Señora de la Asunción, que se localiza en el poblado de Yautepec, el cual alberga en su iglesia y claustro una serie de pinturas murales que afortunadamente todavía se conservan, aunque éstas no han sido objeto de un estudio cuidadoso. ${ }^{1}$ En este sentido, aprovecho la oportunidad para realizar un acercamiento con la finalidad de elaborar un breve análisis que me permita vincular al gunas delas pinturas de dicho convento con el tratado de arquitectura de Sebastián Serlio, ya que tanto sus postulados como las ilustraciones reproducidas en su Libro Quarto, fueron empleados para llevar a cabo la decoración pictórica en al gunas zonas específicas, como las bóvedas y muros del claustro.
1 Un excelente estudio monográfico de conjunto en tomo a varios de los conventos dominicos de la zona de Morelos, puede consultarse en la obra de Hermelinda Cásares Gil e Ima Priscila Harfush Meléndez, La predicación dominica en el siglo XVI . El caso de sus monasterios en el actual estado de Morelos. Esta investigación, producto de una acuciosa labor de reconstruoción histórico-artística, fue presentada por ambas académicas como tesis de licenciatura en 1995, la cual fue galardonada con el premio Marcos y Celia Maus que otorga la FFL de la UNAM a la mejor tesis de licenciatura de ese año. Agradezco a la maestra Hermelinda Cásares el haberme proporcionado un ejemplar de su investigación, que desafortunadamente permanece inédita, ya que fue fundamental para poder elaborar este artíarlo. 
El área geográfica que ocupa actual mente el estado de Morel os se ubica dentro de las zonas que fueron consideradas como puntos claves dentro de Mesoamérica. En efecto, desde la época Preclásica diversos puebl os habitaron la zona, al gunos de ellos de clara filiación ol meca como sería el caso de los habitantes de Chal catzingo y otros más vinculados con la tradición del Altiplano Central, como sería el caso de los grupos nahuas que se establecieron hacia el año 500 d. C. en Xochicalco. Sin embargo, será durante la época del Posclásico, a raíz de la caída del imperio tolteca, que grupos procedentes del norte atravesaron la frontera mesoamericana y se diseminaron por varios lugares; esta dispersión, propició que llegaran al estado de Morelos los xochimilcas y después los tlahuicas.

Los xochimilcas se extendieron hacia el orientey el sur, fundando Tetela, Hueyapan, Tepoztlán, Totolapan y Xumiltepec y establecieron el señorío de Huaxtepec que ocupaba la parte oriente de la zona morelense. Por su parte, los tlahuicas fundaron lo que después se conocería como el Señorío de Cuauhnáhuac (Cuernavaca), estableciéndose en la parte occi dental y mezclándose con los puebl os que ya se habían asentado en esos lugares.

Cuando los mexicas iniciaron su política de expansión, bajo el mando de I zcóatl, gobernante entre 1427 y 1440 , se internaron en la zona de Morel os y mediante diversas operaciones militares lograron apoderarse entre 1430-1437 de dicho territorio, mismo que fue dividido entreTenochtitlan y sus aliados de Texcoco; esta dominación duró hasta la llegada de los españoles.

Los territorios subordinados a la Triple Alianza fueron obligados a tributar diversos productos, sin embargo, los textiles fueron de los artículos más preciados, ya que en la zona se producía al godón de excel ente calidad, aunque también sus habitantes fueron obligados a entregar otro tipo de materias primas, que variaron de acuerdo al clima de las distintas regiones. De acuerdo con lo consignado eilustrado en el Códice Mendocinoy como bien señala del Paso y Troncoso, Yautepec, lo mismo que otros puebl os dela región, tibutaban 
[...] diversas cargas demantas, unas labradas, no pocas adornadas, en general, hechas de algodón; mantillas, mastates (máxtlatl), huipiles, enaguas; igual mente armas, rodelas (escudo o chimalli) con vistosas plumas y flechas para la guerra; frijoles, chian, huautli o semilla de bledos, maíz, cántaros con miel; papel (ámatl o amate) en enormes cantidades (miles de pliegos), hechos de fibra del maguey, pieles de venados; jícaras, petates o esteras; cal, leña, vigas, tablones; aguilas vivas. ${ }^{2}$

Unos años después de consumada la conquista de la ciudad de México-Tenochtitlan, Hernán Cortés reci bió el 6 de julio de 1529 por parte de la Corona española, los títul os de Marqués del Valle de Oaxaca y Capitán General de la Nueva España, así como el dominio señorial sobre una amplia porción de tierras, quese denominaron Estado del Marquesado del Valle de Oaxaca. La Real Cédula especificaba lo siguiente:

Por la presente vos hacemos merced, gracia e donación pura perfecta y no revocable que es dicha entre vivos para agora e para siempre jamas de las villas y pueblos de Cuyoacan, Atlacubaya, Matlazingo, Toluca, Calimaya, Guanavaca, Guastepeque, Acapixtla, Yautepeque, Tepoztlan, Oaxaca [...] que son en la dicha Nueva España hasta un número de 23000 vasal los con sus tierras, o al deas y terminos y vasallos, y jurisdicción civil, y criminal, alta y baja mero mixto imperio, erentas y oficios y pechose derechos, y montes y prados, y pastos e aguas corrientes estantes y manantes y con todas las otras cosas que nos tuvieremos y llevaremos y nos perteneciere y de que podamos y debamos gozar y llevar en las tierras que para nuestra Corona Real se señalaren en dichas villas y pueblos de suso declarados pertenecientes en cualquier manera, para que todo ello sea vuestro y de vuestros herederos y subcesores y de aquel o de aquellos que de vos o de ellos obieren título o causa, y razón. ${ }^{3}$

Una de las zonas del Marquesado abarcaba $4100 \mathrm{~km}^{2}$ de lo que hoy es el estado de Morelos, fungiendo la ciudad de Cuernavaca como al cal día mayor y cabecera. Esta jurisdicción fue la de mayor extensión e importancia, ya que comprendió la casi totalidad del territorio morelense. La alcaldía incl uyó los corregi mientos de Yecapixtla y Oaxtepec, así como ochenta poblados más, ocho haciendas y dos ingenios de caña de azúcar. A partir de la
Colección de Mendoza o Códice Mendocino. Facsímile fototípico dispuesto por Francisco del Paso y Troncoso en 1925, p. XI, fojas $24 \mathrm{r}$.yv.y $25 \mathrm{r}$.También se recomienda la consulta de N. Molins

Fabrega, El Códice Mendocino y la economía de Tenochtitlan, ya que en esta obra el autor realiza un análisis comparativo del tipo de productos que se tributaban a México-Tenodhtitl an y las zonas que distribuían los diferentes artículos.

3 Manuel Mazari, Bosquejo histórico del estado de Morelos, p. 106. 
Acta Capitular 1548.

Nonum Capitulum

Provinciale. Citada en $\mathrm{H}$.

Cásares y I. Harfush, op.

cit., p. 143. Las autoras

señalan que las Actas

Capitulares que incluyen en

su tesis, fueron consultadas

en el archivo personal del

padre Ángel Melcón, O.P.

Ibid. ,

p. 167.

Robert Ricard, La conquista espiritual de México, p. 148.

concesión otorgada a Cortés, y gracias al clima delazona, el cultivo más importante fue la caña de azúcar, la cual sustituyó al al godón como principal producto de la región, convirtiéndose así en la base de la economía morelense aún hasta nuestros días. Asimismo, Ia riqueza natural del suelo permitió que también se realizaran numerosos plantíos de diversos frutos. Para 1551 el oidor Quesada llevó a cabo una inspección en la jurisdicción morel ense y estimó que había al rededor de 15000 tributarios en Cuernavaca y sus estancias, 5500 en Yautepec y Tepoztlán, 4500 en Oaxtepec y las Amil pas y 5000 en Yecapixtla y las Tlalnahuas. ${ }^{4}$

Con relación a la evangelización de la zona, en 1525 los frailes franciscanos fueron los primeros en fundar un monasterio en Cuernavaca. Posteriormente tanto los dominicos como los agustinos instituyeron casas similares; los primeros en Oaxtepec y los segundos en Yecapixtla. Centrándonos concretamente en el caso de los dominicos, la doctrina de Oaxtepec se dividiría con la construcción de los conventos de Yautepec, Tepoztlán y Tlaltizapán, 5 ocupándonos nosotros del primero.

\section{EL CONVENTO DOMINICO DE YAUTEPEC}

En 1548 se autorizó la fundación del segundo establecimiento dominico en Morelos, el cual fue instaurado en el poblado de Yautepec. En el acta capitular de 1548 se menciona Aceptamus domum S. Dominici de Yahutepec. ${ }^{6}$ Cabe mencionar que en este mismo año se fundaron los conventos de Puebla y Yanhuitlán, lo que se estipula en la misma acta. Estas fundaciones se hicieron bajo el provincialato de fray Domingo de Santa María y fungieron como definidores los frailes Domingo de Betanzos, J ordán Bustillo, J uan López y Domingo de la Anunciación; asimismo, en el capítulo de 1552 se menciona Yautepec, en las orillas del río que tiene el mismo nombre. ${ }^{7}$ Yautepec significa "en el cerro del yautli", misma que es

[...] una planta cuyo tallo tiene un codo de largo, hojas semejantes a las del sauz, pero dentadas, las flores amarillas 
y las raíces sutiles. Las flores y las hojas tienen el mismo sabor y olor del anís. Entre los prehispáni cos era una planta muy estimada para usos en la medicina y en las ceremonias religiosas y era natural que Ilevaran su nombre los lugares en los que se sembraba y producía. $^{8}$

Yautepec fue desde época prehispánica uno de los señoríos más importantes de la región, ya que su tlatoani dominabaa los señores de Atlahuelic, Coacalco, Huitzilan, Itzamatitlan y Tlaltizapan; esta sujeción se comprueba cuando el propio Cortés, al recibir entre sus posesiones diversas zonas de la región morelense, afirmó que una buena partede los señoríos estaban sujetos a cinco tlatoque principales, entre los que se encontraba el de Yautepec. ${ }^{9}$

El poblado pasó a formar parte de una de las Cuatro Villas del Marquesado de Cortés, ya que el conquistador dividió Oaxtepec en cuatro jurisdicciones, quedando fraccionadas en Guastepec [sic], Yautepec, Tepuztlan [sic] y Yecapixtla. En 1580 J uan Gutiérrez de Liébana, alcal de mayor de las villas, presentó relaciones separadas, describiendo cada una de éstas, aunque desafortunadamente la de Yautepec se ha perdido. ${ }^{10}$

Como ya hemos señal ado, el primer establecimiento dominico en la región fue el convento de Oaxtepec, el cual fue instaurado en 1528 y 20 años después, en 1548, se realizaría la fundación en Yautepec. El hecho de que mediara tanto tiempo entre la erección de uno y otro establecimiento, podría explicarse si tomamos en consideración que la orden, en este periodo, fundó conventos en Oaxaca (1529), Amecameca (1537), Teposcolula (1541), Tlaxiaco (1548) y Villa Alta (1548), ${ }^{11}$ por lo que es muy probable que todas estas fundaciones retrasaran el desarrollo de las misiones en la zona morelense. A partir de 1548 la evangelización por parte de los dominicos del territorio que hoy ocupa Morelos, quedó en manos de los conventos de Oaxtepec y Yautepec, hasta que en 1555 se fundó el monasterio de Tepoztlán, momento en el que pudieron dividirse la tarea de conversión de losindios de la zona.

Nuestra Señora de la Asunción de Yautepec, es de los pocos conventos del que conocemos el nombre de su constructor: fray Lorenzo de la Asunción, quien llegó a la
8 Cecilio Robelo, Nombres geográficos mexicanos del estado de Morelos, pp. 73-75. Gerhard, qp. cit ., pp. 96-97. 10 Ibid. , pp. 98 y 100; puede consultarse también a René Acuña, Relaciones Geográficas del siglo XVI, México, p. 179.

11 George Kubler, Arquitectura Mexicana del siglo XVI, $3^{a}$ reimp., pp. 69-70. 
12 Ibid., p. 639 y Martha Fernández, "La arquitectura monástica de la Orden de Santo Domingo", en Historia del Arte Mexicano. Arte Colonial II, p. 671.

13 Citado en Jorge Alberto Manrique, Los dominicos y Azcapotzalco, p. 30.

14 Cásares y Harfush, qp. cit., p. 145 .

15 Antonio de Ciudad Real, Tratado curioso y docto de las grandezas de la Nueva España, vol. II, p. 60.

16 Ibid., p. 30. Asimismo, el autor presenta una semblanza biográfica de este connotado fraile. Ibid, pp. 30-32.
Nueva España en 1554; este fraile también fue el encargado de construir el convento dominico de Azcapotzal co y Tacubaya, ${ }^{12}$ según afirmó el cronista Alonso Franco y Ortega: “[...] débele la Provincia a este siervo de Dios los edificios que hoy tieney goza en los conventos de Atlacubaya, Azcapotzal co y Yautepec [...]."13

En 1558 fray Lorenzo de la Asunción fue designado vicario del convento y éste puede ser un dato de gran importancia, que aunado con la mención del cronista Franco y Ortega, puede indicar la fecha de inicio de la construcción del conjunto conventual. Asimismo, para poder ubicar esa fecha, se cuenta con una inscripción que aparece en el extremo derecho de la fachada principal del templo la cual dice: "AÑO DE 1567 AÑO PONTIFFICAT PIO V N.I. REGNAN TEPHILPOZ...".14 Esta inscripción podría indicar la fecha de conclusión del mismo o por lo menos, un adelanto significativo en las obras de edificación del conjunto conventual. No obstante, para la década de los años ochenta del siglo XVI quizá el convento pudo haber sido concluido, ya que el cronista Antonio de Ciudad Real menciona que durante su travesía en octubre de 1586, el comisario franciscano "[...] Il egó a otro buen pueblo Ilamado Yautepec, donde hay otro convento de Santo Domingo". ${ }^{15}$

Por otra partey como bien ha señaladoJ orgeAlberto Manrique con relación a la participación de fray Lorenzo dela Asunción en las obras de construcción del convento de Azcapotzalco, no sabemossi en realidad fue el encargado de dirigir la edificación de los conjuntos conventuales en los quese menciona su participación, sin embargo, a decir del mismo investigador:

[...] aunque fray Lorenzo no haya sido el arquitecto propiamente dicho, parece seguro que tuvo participación activay determinante en las obras que se le atribuyen; esto se desprende de la importancia que da el cronista [Franco y Ortega] en la vida del padre de la Asunción a la construcción de Iosconventos, y, sobretodo, al hecho de que los tres conventos que se citan tienen mucha relación entre sí, especialmente los de Azcapotzal co y Tacubaya en donde las semejanzas van más allá de general idades y se encuentran aún en detalles menores. Si fray Lorenzo contó con al gún alarife parallevar a cabo las obras, es muy probable que él mismo haya impuesto su criterio en las fábricas. ${ }^{16}$ 
Como ya lo han anotado numerosos especial istas del arte novohispano del siglo XVI, debi do a la carencia de artífices que llevaran a cabo la edificación de los conventos, muchas veces los frailes se encargaron de di rigir las obras constructivas, apoyados en tratados arquitectónicos que les sirvieron de model o, lo cual se constata a través de las crónicas de la época, además de que:

Un elemento que refuerza esta idea, es la presencia de dichos tratados en las "librerías" tanto de los conventos de las órdenes mendicantes, como en la de otras órdenes e instituciones religiosas, en cuyos acervos se han detectado los siguientes volúmenes: De ReAedificatoria de Alberti, edición de 1541, en la biblioteca del convento de San Francisco de la Ciudad de México; dos ejemplares del Tercero y Cuarto libro de arquitectura de Serlio, de la edición de 1545 con textos en francés e italiano; el tratado de Viñola Reglas de los cinco órdenes de arquitectura, en su edición italiana de 1617 en los fondos del Colegio Máximo de San Pedro y San Pablo, y Los diez libros de arquitectura de Marco Vitruvio Polión, edición latina de 1567 en el Convento del Carmen y otra edición italiana del mismo año, en el colegio de San Francisco Xavier de Tepotzotlán. ${ }^{17}$

El tratado de Serlio fue de particular importancia en el ámbito arquitectónico de la Nueva España, ya que existen constantes referencias de su utilización, desde el siglo XVI hasta el XVIII. Sebastián Serlio (ca. 1475-1554) fue uno de los artífices ital ianos más importantes vinculados con el manierismo; fue pintor y arquitecto y su tratado Regole Generali di Architettura, dividido en ocho libros publicados a lo largo de su vida, constituye uno de los "cuatro grandes tratados de arquitectura del siglo XVI, y muy pronto al canzó un favor poco común dentro y fuera del talia, como atestiguan sus numerosas ediciones y traducciones [...]". ${ }^{18}$ En este sentido, anotaremos al gunas consideraciones en torno a cómo fue empleado el tratado serliano, particularmentesu Libro Quarto deArchitectura en la decoración del convento de Yautepec, de Nuestra Señora de la Asunción cuenta con las dependencias propias de los conventos construidos durante el siglo XVI, aunque para los fines de este artículo, únicamente abordaremos aquel las partes en donde se conservan restos de pintura mural, misma que se local iza en la iglesia y en el claustro bajo del convento.
17 Oscar H. Flores Flores, Reflexiones sobre los tratados de arquitectura y su influencia en la Nueva España durante la primera mitad del siglo XVIII: los testimonios del arquitecto José Eduardo de Herrera en torno a la construcción de la Real Casa de Moneda, p. 19. Investigación presentada por el autor como tesis para obtener el grado de maestro en Historia del Arte.

Sobre este tema también se recomienda la consulta de Er nesto de la Torre Villar, Ia arquitectura y sus libros. Guía bibliográfica para la historia $y$ desarrollo de la arquitectura y el urbanismo en México.

18 Joaquím Garriga, Fuentes $y$ documentos para la Historia del Arte. Renacimiento en Europa, pp. 366-367. Con relación a esta obra, es importante señalar que fue de particular importancia el Libro Cuarto, ya que "[...] va asociada a la teoría de los cinco órdenes, fijada ya desde hacía tiempo en Italia e identificada en toda Europa con la arquitectura

"renacentista", Ibid., p. 367. 
La iglesia es muy sencilla al igual que su fachada: en la parte superior fue colocada una ventana rectangular que permitelailuminación del coro al to y su portada, deun riguroso esti lo clásico, seencuentra estructurada por dos pares de pilastras toscanas, quea cada uno de los lados flanquean el vano de ingreso; estos apoyos de fuste estriado, sostienen un friso decorado con triglifosy metopas, el cual es rematado por una cornisa. De acuerdo con los estudios real izados por George Kubler, esta fachada puede inscribirse dentro de aquellas que eran pintadas para poner de relieve los trazos de la mampostería. ${ }^{19}$

El templo cuenta únicamente con una torre campanario y los dos cuerpos que la conforman probablementeson del siglo XIX, lo mismo que el cupulín que la remata. Asimismo, la iglesia se encuentra cubierta con una bóveda de cañón corrido, sostenida con un sistema de contrafuertes en disposición diagonal, los cual es tienen una al mena decorativa en el remate de cada uno de ellos. En su interior aún se puede apreciar decoración de pintura mural, particularmente en la zona del sotocoro, la que por fortuna se encuentra en buen estado de conservación. Estas pinturas simulan las nervaduras de una bóveda, colocándose en cada uno de los cruces grandes círculos que ostentan, entre otros temas, anagramas de Cristo, escudos dominicos, un escudo franciscano, un escudo agustino y los símbolos de María. Estas pinturas muestran una gama cromática muy rica, aunque predomina el tono rojo y al gunas partes tienen como fondo el col or verde. Asimismo, en la zona del coro se pueden apreciar pinturas que muestran decoración geométrica intercalada con estrellas, realizadas en tonos rojizos. ${ }^{20}$

La igl esia está dividida en cinco tramos más el ábside, y como ya mencionamos, está cubierta con bóveda de cañón corrido. En varias de estas zonas se pueden apreciar fragmentos de pintura, lo que permite inferir que seguramente el templo contó también con decoración pictórica a lo largo de los muros de la nave, muchos de los cuales se encuentran, en la actual idad, total mente encal ados.

El claustro es de pequeñas dimensiones y fue construido con tres vanos por cada unos de sus cuatro lados. Para edificar sus dos plantas, los constructores utilizaron contrafuertes como el ementos arquitectónicos de apoyo, los 
que en la parte inferior presentan para su sostén machones cuadrados, mientras que en la superior, los contrafuertes tienen forma prismática. El claustro al to se encuentra techado con bóveda de cañón y únicamente se conservan al gunos fragmentos de decoración pictórica semejantes a la cenefa que se localiza en el claustro bajo.

Los pasillos del claustro bajo también fueron techados con bóvedas de cañón corrido, mismas que presentan decoración pictórica de figuras hexagonales con motivos floral es al centro, las cual es, como bien ha señalado la maestra I sabel Estrada de Gerlero, ${ }^{21}$ probablemente se encuentren inspiradas en los grabados que ilustran diversos libros, particularmente el Libro Quarto de Architectura de Sebastián Serlio, en el que aparecen dibujados dichos hexágonos cuando explica los cielos Ilanos de madera y sus ornamentos:

[...]Y ansi digo, quesi el cielo de una sala, o de otra pieza, fuere de grande alto, que el compartimiento de la obra que en el se oviere de hazer, sea de obra gruessa, y de forma espaciosa, y de grandes hondos, y de muy buen relievo, porque por el gran al to en que estan, venga a disminuir algun tanto, y a corresponder bien en la vista de abaxo. Y ansi mismo si seadornare de pintura, deve ser de cosas gruessas, conforme al tal alto y grandeza. Y esta pintura en tal caso, mas ayna se a de hazer de blanco y negro, o claro y escuro, que de muchas colores, porque las cosas destas colores pintadas, tienen mayor fuerza, lo cual han acostumbrado y hecho assi todos los pintores de buen juyzio en sus obras en semejantes lugares. ${ }^{22}$

J ustamente en Yautepec predomina la combinación blanco y negro, aunque presenta leves toques de tonos rojizos; en muchos de ellos hay grandes círculos donde se representan los anagramas de J esús, de María, el escudo dominico, el Sol y la Luna con rayos. Esimportantemencionar que posi blementelos postulados del tratado de Serlio pudieron ser aplicados en el caso dela decoración deestas bóvedas, y no sólo como un repertorio de model os o ilustraciones, lo cual nosinduceapensar quelostratadossetomaban en consideración desdeel punto de vista teórico y práctico.

Por debajo de la pintura que cubre las bóvedas, fue colocada una cenefa con grutescos que incluye angelillosy animales fantásticos entrelazados con motivos vegetal es.
21 Elena I. Estrada de Gerlero, "La pintura mural durante el Virreinato", t. 7, p. 1027.

22 Sebastián Serlio, Ter ceroy Cuarto Libro de Arquitectura, "Libro Quarto", pp. s/n [IXXII vuelto]; se respetó la ortografía original del texto. Vid., también el dibujo de la lámina en la página LXXV. 
Cada par de ángel es sostiene un blasón que representan símbolos vinculados con la orden dominica, con la Pasión deCristo (la daga, la columna, las tenazas o pinzas y el gallo), o con la I gl esia en general, como son latiara papal, el báculo y un libro.

En el claustro bajo, en cada uno de los muros que hay entre vano y vano, también se representaron santos dominicos y otras figuras prominentes de la I gl esia católica; entre los personajes que fueron incluidos tenemos los siguientes:

Santo Domingo de Guzmán

Papa Pío V

Papa Benedicto XI

San Vicente Ferrer

San Pedro Mártir de Verona

San Telmo

Santo Tomás de Aquino

San Ambrosio

San J erónimo

Santa Lucía de Bolonia

Santa Catalina de Siena

San Francisco de Asís

San Antonio de Florencia

Cabe mencionar que por encima de las imágenes de estos santos, hay una cenefa con grutescos basados en decoración vegetal combinada con animales. Asimismo, en este claustro hay nichos en cada una de las esquinas, los que muy probablemente también fueron decorados con pintura mural, aunque en la actualidad no quedan restos de la misma.

Retomando nuevamente los postulados enunciados por Sebastián Serlio, el tratadista menciona lo siguiente con respecto a la decoración pictórica de los edificios:

[...] Digo, que el arquitecto no solamente deve ser curioso en los ornamentos que han de ser de piedra y de marmol, pero tambien lo deve ser en la obra y pintura del pinzel para adornar las paredes y otras partes de los edificios, y principalmente le conviene ser el mismo ordenador de todo como superior de todo lo que se aya de hazer en las obras: porque si no lo es, podria topar con al gunos pintores tan presuntuosos en las palabras y en saber estimarse, 
cuanto en las obras de poco juyzio: Ios quales no han tenido $\mathrm{ni}$ tienen respecto a mas de mostrar las differencias de las colores, sin consideracion a otra cosa ninguna, y con esto muchas vezes han corrompido la orden que se deve tener en las tales cosas, no tiniendo cuenta de poner la pintura en su lugar, y los coloridos donde son necessarios [...] Y si acaso quisiere solamenteel pintor complazer al señor de la obra con la diversidad de las colores, por no dañar ni romper la obra como ya esta dicho, se podran fingir algunos lienzos o paños colgados de la pared como cosa mobible, en los quales se puede poner y colgar lo que mas apazible les parezca, porque desta manera no se corrompe la orden: y fingiran la verdad guardando su origen. Podra tambien a uso de triunphos y fiestas pintar algunas hermosas ficciones, en las quales podra hazer festones de hojas y defrutasy de flores, escudos, tropheos, y otras cosas como estas coloridas de muchas maneras que representassen cosas colgadas y mobibles. ${ }^{23}$

Estos postuladostambién seadecuan al tipo de decoración que fue realizada en el claustro bajo del convento de Yautepec, ya quetodas las figuras de lossantos que hemos mencionado líneas arriba, presentan características similares en cuanto a la representación de "lienzos" o "paños fingidos", de los cuales retomaremos cuatro ejemplos:

1. Santo Domingo. La representación del santo, colocada en el muro poniente del claustro bajo, es de una calidad pictórica extraordinaria, ya que no sól o es una figura de gran presenciafísica, sino que se encuentra enmarcada en una especie de nicho en el cual seapoya como si fuese una escultura. Asimismo, el enmarcamiento es notable por su riqueza decorativa, ya que reproduce un par de coIumnas laterales que presentan elementos ornamentales propios del grutesco, como son los rostros de perfil que se encuentran representados en cada una de ellas.

2. Benedicto XI. La representación del pontífice también se ubica en el muro poniente del claustro bajo, y podemos identificarlo gracias a una inscripción que se conserva en la parte superior del extremo derecho del mismo: "BENEDI/ CTUS/ XI". De esta figura, Io mismo que San Francisco que a continuación mencionaremos, sólo se conserva la parte media superior del cuerpo, el cual porta la tiara, el báculo papal y un libro. El personaje
23 Ibid, , p. s/n [IXXI vuelto]; se respetó la ortografía original del texto. 
presenta una posición de tres cuartos y el enmarcamiento en el cual fue ubicado es sumamente sencillo, ya que simula una puerta.

3. San Francisco de Asís. Enmarcado en una rica decoración vegetal, "el pobre de Asís" fue representado en el muro sur del claustro bajo. Desafortunadamente, de esta pintura mural sólo se conserva la imagen de medio cuerpo, el cual corresponde a la parte media superior. EI santo, con las manos levantadas, porta en la derecha un crucifijo y en la izquierda muestra el símbolo de los estigmas; sobre su cabeza también fue colocada una inscripción que nos permite confirmar su identificación: "ES FRANCISCO". La imagen es sumamente interesante, ya que a diferencia de las otras figuras de santos que aún se pueden apreciar en este claustro, se encuentra total mente proyectada hacia el frente, solución pictórica que produce el efecto de que el personaje "sale" del marco que lo encuadra, pues además también se observa cómo el brazo izquierdo se apoya sobre el enmarcamiento; todos estos elementos proporcionan un efecto visual de tridimensionalidad en la figura.

4. San Telmo. Personaje localizado en el muro norte del claustro bajo, cuya inscripción en el extremo superior derecho "S.TEL/ MUS" nos permite su identificación, lo mismo que al gunos de sus atributos. San Telmo, quien en realidad se llamaba Pedro Gonzál ez, profesó en la orden de Santo Domingo en el siglo XIII. Este santo acompañó al rey Fernando III en suscampañas de reconquista de la Península I bérica y murió en 1246. Según Roig, a San Telmo en ocasiones se le confunde con San Erasmo, quien fuera obispo de Antioquia y Formia durante el gobierno de Diocleciano. Esta confusión surge de que ambos santos son consi derados como patrones de los marineros, el primero de la costa cantábrica y el segundo en la mediterránea; sin embargo, sus fiestas son celebradas en fechas distintas: Ia de San Telmo o Pedro González, el 15 de abril y la de San Erasmo, el 2 de junio. ${ }^{24}$

En el caso de esta representación, sus atributos se encuentran bien diferenciados: viste el hábito blanco y negro de los dominicos, además de que también porta 
una llama o vela encendida (fuegos de San Telmo). ${ }^{25}$ De esta figura también se conserva un rico enmarcamiento, del cual resalta la figura del santo, aunque en la parte inferior derecha se ha perdido parte de la decoración.

\section{CONSIDERACIONES FINALES}

La importancia del tratado de Sebastián Serlio en el arte virreinal fue fundamental, ya que además de haber tenido una enorme influencia en la arquitectura conventual, particularmente en las portadas de los templos, en el caso de la pintura mural también tuvo un lugar destacado, como puede apreciarse en diversos conventos, cuyos programas decorativosincluyen elementos procedentes de dicho tratado.

Un ejemplo de lo anterior, es el convento de Nuestra Señora delaAsunción deYautepec, Morelos, en dondelospostulados de Serlio fueron aplicados de manera práctica, no sólo como modelo a través de la utilización de las láminas que se encuentran reproducidas en su Libro Quarto, sino también siguiendo las indicaciones que el arquitecto señala como adecuadas para decorar con pintura los edificios.

En este sentido, los frailes y los artífices que participaron en la construcción y decoración del convento, no hacían sino continuar con una tendencia muy común, tanto en el virreinato como en la Europa de la época, en la cual la utilización de los tratados renacentistas, y en particular los manieristas, fueron empleados no sólo porque ofrecían una serie desoluciones a problemas técnicos concretos, sino porque brindaban un amplio repertorio de motivos formales procedentes del mundo clásico, por lo que su incorporación a los programas decorativos de los conjuntos conventual es novohispanos, además de retomar un referente visual y cultural de reconocido prestigio, es un fiel reflejo del pensamiento humanista presente en la Nueva España desde los primeros años de evangelización.
25 En ocasiones, este santo también es representado con diferentes atributos que aluden a sus obras, por ejemplo, portando una pequeña nave; con un puente, que hace referencia al que construyó en Rivadavia, sobre el río Miño o bien, con peces que aluden a un milagro producido por el santo en una ocasión en la cual los trabajadores que construían dicho puente no tenían que comer. Ibid., p. 254. 
ACUÑA, René, Relaciones Geográficas del siglo XVI: MéxiCo, tomol, volúmen 6. México, IIA-UNAM, 1985, (Serie Antropológica 63).

CÁSARES GIL, Hermelinda e Irma Priscila Harfush Meléndez, La predicación dominica en el siglo XVI. El caso de sus monasterios en el actual estado de Morelos. México, 1995. Tesis, UNAM, Facultad deFilosofía y Letras.

CIUDAD REAL, Antonio de, Tratado curioso y docto delasgrandezas de la Nueva España, vol. II , edición, estudio, apéndices, glosarios, mapaseíndices deJ osefinaGarcía Quintanay Víctor M. Castillo Farreras, México, IIH-UNAM, 1993 (Serie Historiadores y Cronistas de Indias/6).

Colección de Mendoza o Códice Mendocino. Facsímile fototipico dispuesto por Francisco del Paso y Troncoso en 1925, México, Editorial Innovación, 1980.

ESTRADA DE GERLERO, Elenal., "Sentido político, social y religioso en la arquitectura conventual novohispana", en Historia del Arte Mexicano. Arte Colonial I, vol. 5, 2a. ed., México, SEP/ SALVAT, 1986, pp. 624-643.

_'La pintura mural duranteel Virreinato", en Historia del ArteMexicano. Arte Colonial III, vol. 7, 2a. ed., México, SEP/ SALVAT, 1986, pp. 1011-1027.

FERNÁNDEZ, Martha, "La arquitectura monástica de la Orden de Santo Domingo", en Historia del Arte Mexicano. Arte Colonial I, vol. 5, 2a. ed., México, SEP/ SALVAT, 1986, pp. 667-685.

FLORES Flores, Oscar H., Reflexiones sobre los tratados de arquitectura y su influencia en la Nueva España durante la primera mitad del siglo XVIII: Ios testimonios del arquitectoJ osé Eduardo de Herrera en torno a la construcción de la Real Casa de Moneda. México, 2007. Tesis, UNAM, Facultad de Filosofía y Letras.

GARRI GA, J oaquim (ed.), Fuentes y documentos para la Historia del Arte. Renacimiento en Europa. Barcelona, Gustavo Gili, 1983.

GERHARD, Peter, Geografía histórica de la Nueva España 1519-1821. México, IIH-UNAM, I nstituto de Geografía, 1986. (Espacio y tiempo/ 1)

KUBLER, George, Arquitectura Mexicana del Sigloxvı. $3 a$. reimp., México, FCE, 1992. 
MANRIQUE, J orge Al berto, Los dominicos y Azcapotzalco. núm. 17. México, Cuadernos de la Facultad de Filosofía, Letras y Ciencias, Universidad Veracruzana, 1963.

MAZARI, Manuel, Bosquejo histórico del estado de Morelos. México, s/e, 1966.

Molins Fabrega, N., El Códice Mendocino y la economía de Tenochtitlan. México, Libro-Mex. Editores, 1956 (Biblioteca Mínima Mexicana, vol. 30).

Noguez, Xavier, "La zona del Altiplano central en el Posclásico: Ia etapa tol teca", en Linda Manzanilla y Leonardo López Luján, coord., Historia Antigua de México. vol. III. México, UNAM-INAH, Miguel Ángel Porrúa, 1995.

OBREGÓN Rodríguez, María Concepción, “La zona del Altiplano central en el Posclásico: la etapa de la Triple Alianza", en Linda Manzanilla y Leonardo López Luján, coord., Historia Antigua de México, vol. III. México, UNAM-INAH, Miguel Ángel Porrúa, 1995.

RICARD, Robert, Laconquista espiritual deMéxico. México, FCE, 1986. (Sección de Obras de Historia)

REYES GARCía, Luis y Lina ODENA GÜEMES, "La zona del Altiplano central en el Posclásico: la etapa chichimeca", en Linda Manzanilla y Leonardo López Luján, coord. Historia Antigua de México. Vol. III, México, UNAM-INAH, Miguel Ángel Porrúa, 1995.

ReYes-VAlerio, Constantino, Arte Indocristiano. MéxiCO, INAH, 2000 (Colección Obra Diversa).

RoBelo, Cecilio, Nombres geográficos mexicanos del estado de Morelos. Cuernavaca, Gobierno del estado de Morelos, 1982. (Summa Morelense)

RoI G, J uan Ferrando, I conografía de los santos. Barcelona, Ediciones Omega, 1991.

SCHENONE, Héctor H., I conografía del Arte Colonial. Los santos. vols. I y II , Buenos Aires, Fundación Tarea, 1992. SERLIO, Sebastián, Tercero y Cuarto Libro de Arquitectura. Ed. Facs. de 1552. Barcelona, Alta Fulla, 1990. (Serie "Artey Arquitectura", 6).

TORRE Villar, Ernesto de la, La arquitectura y sus libros. Guía bibliográfica para la historia y desarrollo de la arquitectura y el urbanismo en México. México, UNAM-IIB, Coordinación de Humanidades, 1978. 
